Saldanha, S., P. D. Taylor, T. L. Imlay, and M. L. Leonard. 2019. Biological and environmental factors related to communal roosting behavior of breeding Bank Swallow (Riparia riparia). Avian Conservation and Ecology 14(2):21. https://doi.org/10.5751/ACE-01490-140221

Copyright (C) 2019 by the author(s). Published here under license by the Resilience Alliance.

Research Paper

\title{
Biological and environmental factors related to communal roosting behavior of breeding Bank Swallow (Riparia riparia)
}

\author{
Sarah Saldanha ${ }^{1}$, Philip D. Taylor ${ }^{2}$, Tara L. Imlay ${ }^{1}$ and Marty L. Leonard ${ }^{1}$ \\ ${ }^{1}$ Biology Department, Dalhousie University, Halifax, Nova Scotia, Canada, ${ }^{2}$ Biology Department, Acadia University, Wolfville, \\ Nova Scotia, Canada
}

\begin{abstract}
Although communal roosting during the wintering and migratory periods is well documented, few studies have recorded this behavior during the breeding season. We used automated radio telemetry to examine communal roosting behavior in breeding Bank Swallow (Riparia riparia) and its relationship with biological and environmental factors. Specifically, we used (generalized) linear mixed models to determine whether the probability of roosting communally and the timing of departure from and arrival at the colony (a measure of time away from the nest) was related to adult sex, nestling age, brood size, nest success, weather, light conditions, communal roosting location, and date. We found that Bank Swallow individuals roosted communally on $70 \pm 25 \%$ of the nights, suggesting that this behavior is common. The rate of roosting communally was higher in males than in females with active nests, increased with older nestlings in active nests, and decreased more rapidly with nestling age in smaller broods. Together, these results suggest that that communal roosting is limited by the thermoregulatory needs of the offspring. The rate of roosting communally and the total time spent away from the nest while roosting also decreased with humidity and low temperatures (total time only), supporting the conclusion that the thermoregulatory needs of both offspring and adults limit this behavior. Communal roosting was also restricted to dark nights, suggesting that the Bank Swallow may roost communally to avoid predation. Individuals also roosted communally and spent more time at the roosts as the breeding season progressed, suggesting that communal roosting may be a way of avoiding the growing number of ectoparasites at the colony or taking advantage of prospecting opportunities in the morning. The Bank Swallow is listed as Threatened in Canada, so understanding the factors that relate to communal roosting is essential for identifying the critical habitat of this declining species.
\end{abstract}

\section{Facteurs biologiques et environnementaux liés au comportement de nidification communautaire de I'hirondelle de rivage (Riparia riparia) pendant la saison de reproduction}

RÉSUMÉ. Bien que la nidification communautaire au cours des périodes d'hivernage et de migration soit bien documentée, rares sont les études qui ont enregistré ce même comportement au cours de la saison de reproduction. Nous avons utilisé la radio-télémétrie automatisée pour examiner le comportement de nidification communautaire de l'hirondelle de rivage (Riparia riparia) en période de reproduction et sa relation avec les facteurs biologiques et environnementaux. Plus précisément, nous avons (généralement) utilisé des modèles linéaires mixtes pour déterminer si la probabilité de nidification communautaire et le moment du départ et de l'arrivée dans la colonie (permettant de mesurer le temps passé en dehors du nid) était liée au sexe chez les adultes, à l'âge de nidification, à la taille de la couvée, à l'efficacité du nid, aux conditions météorologiques, à l'emplacement du nid collectif et à la date. Nous avons constaté que les hirondelles de rivage occupaient des nids communautaires lors de $70 \% \pm 25 \%$ des nuits, ce qui suggère que ce comportement est courant. Le taux de nidification communautaire était plus élevé chez les mâles que chez les femelles ayant des nids actifs, augmentait avec la présence d'oisillons plus âgés dans des nids actifs et diminuait plus rapidement avec l'âge des oisillons dans les couvées de petite taille. L'ensemble de ces résultats suggère que la nidification communautaire est limitée par les besoins de la couvée en termes de thermorégulation. Le taux de nidification communautaire et le temps total passé hors du nid pendant la nidification diminuait également avec l'humidité et les basses températures (en temps total seulement), soutenant l'hypothèse selon laquelle les besoins de thermorégulation des oisillons comme des adultes limitent ce comportement. La nidification communautaire était également limitée aux nuits sombres, ce qui suggère que l'hirondelle de rivage pourrait choisir la nidification communautaire pour éviter la prédation. Les individus nichaient également en communauté et passaient plus de temps dans le nid à mesure que la saison de reproduction avançait, ce qui semble indiquer que la nidification communautaire pourrait être un moyen d'éviter le nombre croissant d'ectoparasites dans la colonie ou de profiter des opportunités de prospection au petit matin. L'hirondelle de rivage est classée parmi les espèces menacées au Canada, de sorte qu'il est essentiel de comprendre les facteurs liés à la nidification communautaire pour identifier l'habitat critique de cette espèce en déclin.

Key Words: automated telemetry; communal roost; habitat use; predator avoidance; radio telemetry; Sand Martin; thermoregulation; weather 


\section{INTRODUCTION}

Animals across a variety of taxa aggregate in groups ranging from a few to millions of individuals over the course of their annual cycle (Krause and Ruxton 2002). These aggregations are hypothesized to benefit individual group members by reducing thermoregulation costs (Beauchamp 1999) and predation risk (Lack 1968) and increasing mating opportunities (Bonduriansky and Brooks 1999), foraging efficiency (Boesch 1994), navigational abilities (Biro et al. 2006), and information transfer (Ward and Zahavi 1973). These benefits are balanced by costs such as increased conspicuousness (Beauchamp 1999), disease transmission (Yom-Tov 1979), and competition (Beauchamp 1999, Bonduriansky and Brooks 1999). Trade-offs between these costs and benefits explain much of the diversity of aggregations observed across taxa (Beauchamp 1999).

In birds, a common aggregation is communal roosting, whereby multiple individuals gather before sunset and spend the night together before dispersing again at sunrise (Alonso et al. 1985, Bijlsma and van den Brink 2005). By roosting communally, birds potentially reduce thermoregulatory costs (Walsberg and King 1980) and predation risk (Morrell and James 2008) while increasing foraging efficiency (Ward and Zahavi 1973, Richner and Heeb 1996). The selection, composition, and occupancy of these communal roosts is related to biological factors such as age, sex, dominance status, and breeding stage (Summers et al. 1987, Curnutt 1992, Blanco 1996, Blanco and Tella 1999, Cougill and Marsden 2004, McVey et al. 2008), and environmental factors such as weather and distance from diurnal activity centers (Krantz and Gauthreaux 1975, Anthony et al. 1981, Alonso et al. 1985, Obrecht and Dinsmore 2008, Lambertucci and Ruggiero 2013). Understanding the relationships between these biological and environmental factors and roosting behavior can help identify the costs and benefits associated with communal roosting and determine the main evolutionary drivers for this behavior.

The factors related to roosting behavior during winter and migratory periods, when communal roosts sometimes number in the millions of birds, have been well documented (e.g., Caccamise et al. 1997, Stolen and Taylor 2003, Laughlin et al. 2014). Relatively less is known about the drivers of communal roosting during the breeding season, when the behavior is assumed to be less common. The existing information suggests that during the breeding season, communal roosts are smaller than during the winter and migratory periods and comprise mostly juveniles and subadults (Curnutt 1992, Blanco 1996, Cougill and Marsden 2004, McVey et al. 2008). This information suggests that breeders are not using communal roosts, possibly because of the high cost of leaving eggs or young unattended during the night, when they are vulnerable to thermoregulatory stress and predation (Curnutt 1992, Blanco 1996, Cougill and Marsden 2004, McVey et al. 2008). We know, however, of two tracking studies that suggest that active breeders do occasionally use communal roosts. One male out of 13 radio-tagged Common Blackbird (Turdus merula) roosted away from the nest throughout the breeding season, and its mate left the nest to roost after the young were $11 \mathrm{~d}$ post hatch (Hill and Cresswell 1997). Similarly, radio-tagged Bank Swallow (Riparia riparia) individuals were reported roosting communally during the breeding season (Falconer et al. 2016).
The Bank Swallow provides an excellent model for examining the factors driving communal roosting during the breeding season. Previous work on this species found that adults of both sexes left active nests containing eggs or nestlings to roost in cattail wetlands approximately $30 \mathrm{~km}$ from the breeding colony (Falconer et al. 2016). Females were more likely to remain at the colony than males, suggesting that differences in parental care played a role in the probability of roosting communally, although this factor explained only a fraction of the variation in this behavior (Falconer et al. 2016). Understanding the factors driving communal roosting during the breeding season may be especially important for declining species such as the Bank Swallow (Sauer et al. 2017). In the last 40 years, Bank Swallow populations in Canada suffered a $98 \%$ decline and were listed as Threatened by the Canadian Species At Risk Act in 2017. To fulfill the recovery requirements of the Species At Risk Act, critical habitat will need to be identified and protected. However, this step will only be possible with a full understanding of the importance of all habitats used during the breeding season, including communal roosts.

Our goal was to build on past research by Falconer et al. (2016) by identifying how biological and environmental factors relate to communal roosting by the Bank Swallow during the breeding season, to uncover the drivers of this behavior in both active and inactive nests. Specifically, we used radio telemetry to determine how adult sex, nestling age, brood size, nest success, weather, light conditions, and date related to both the probability of roosting communally, and the departure from and arrival at the colony, as a measure of the total time away from the nest.

We predicted that several factors could relate to the likelihood of communal roosting by the Bank Swallow, including the thermoregulatory needs of the offspring and adults, the risk of collapsing burrows and predation, ectoparasite avoidance, and prospecting opportunities. If communal roosting is limited by the thermoregulatory needs of the offspring, we hypothesized that females, who are the primary incubators and brooders (Petersen 1955), will roost communally less often and for shorter periods than males, and that both sexes will limit this behavior when nests are active, at ages when young are most sensitive to temperature (in late incubation and in the first week after hatching; Dunn 1975, Marsh 1979, Marsh and Wickler 1982, Cooper and Voss 2013, Sirsat et al. 2016), in poor weather conditions (low temperatures and high humidity; Coe et al. 2015), and in nests with small broods that are less able to thermoregulate (Dunn 1975). We also hypothesized that if communal roosting is limited by the thermoregulatory needs of the adults, Bank Swallow individuals will refrain from roosting communally and reduce their time away from the nests while roosting in poor weather conditions (low temperatures, high humidity, high wind). Additionally, if communal roosting is driven by the avoidance of slumping banks and potential burrow collapse, this behavior will be more common during humid nights, when slumping is more likely to occur. Similarly, we hypothesized that Bank Swallow individuals will refrain from communal roosting on bright nights, as do other species with nocturnal predators (Brooke and Prince 1991, Lang et al. 2006), Finally, if communal roosting is driven by parasite avoidance at the colonies or information transfer of nesting success, we expect more birds to roost communally at the end of 
the breeding season, when ectoparasite densities are highest (Burke 2017) and individuals are more likely to prospect potential nesting habitat for the following breeding season (Brown et al. 2000).

\section{METHODS}

\section{Study sites}

Our study was conducted between 16 May and 26 August 2015 at two breeding colonies in New Brunswick, Canada. Tantramar North (TN; $45.905^{\circ} \mathrm{N}, 64.338^{\circ} \mathrm{W}$ ) had 76 pairs of breeding Bank Swallow, and Sackville Engineering (SE; $45.891{ }^{\circ} \mathrm{N}, 64.354^{\circ} \mathrm{W}$ ) had 54 pairs. The latter site was settled later in the season, possibly by birds that moved to the site following an extreme rainfall event that caused many riverbanks to slump, destroying $90 \%$ of the nests in colonies near TN. Consequently, the SE colony had later hatching dates than the birds at TN. Both sites were surrounded by flat pastureland, hayfields, and marshlands, serpentined by the Tantramar River. Bank Swallow nest monitoring and tagging was approved by the Dalhousie University Animal Care Committee (protocol 14-025).

\section{Biological factors}

We checked nesting burrows every $2-3 \mathrm{~d}$ from nest excavation to $12 \mathrm{~d}$ post hatch. From this, we identified the incubation date (i.e., incubation begins on the day the penultimate egg is laid), clutch size, hatching date, brood size, and nestling survival until 12 days post hatch. We were unable to record the incubation date for one nest and the hatching date for three nests because of either poor weather conditions that prevented frequent nest checks or poor visibility of nest contents, which were occasionally obscured by nest materials. Therefore, for these four nests, we estimated the incubation or hatching date by subtracting or adding the mean incubation period for the colony (TN: $16.2 \pm 1.7 \mathrm{~d}, N=35$; SE: $14.1 \pm 0.3 \mathrm{~d}, N=9$ ) to the known hatching or incubation dates, respectively. Nestling age was considered the number of days since incubation began, with negative values representing days before the initiation of incubation, and positive values as days after the initiation of incubation, irrespective of whether the nest failed or the nestlings fledged.

We assumed nests failed if eggs did not hatch by $10 \mathrm{~d}$ after their predicted hatching date or if we found dead nestlings or an empty burrow before the predicted fledging date $(22 \mathrm{~d}$ post hatch; Garrison 1999). Nests were considered active from the incubation date until the nest failed or the nestlings fledged (assumed to be 22 d post hatch; Garrison 1999). We followed 45 (59\%) nests at TN and $22(41 \%)$ at SE that were active for at least part of the breeding season after the extreme rainfall event and were accessible for nest monitoring.

\section{Environmental factors}

We compiled data on the following environmental factors at 20:00 and 06:00 local time to coincide with the approximate times of departure to and return from communal roost sites: temperature $\left({ }^{\circ} \mathrm{C}\right)$, wind speed $(\mathrm{km} / \mathrm{h})$, relative humidity $(\%)$, and cloud cover (1-4, 1 being clear and 4 being overcast). Cloud cover was recorded at the Greater Moncton Romeo LeBlanc International Airport weather station $\left(46.112^{\circ} \mathrm{N}, 64.676^{\circ} \mathrm{W}, \sim 36 \mathrm{~km}\right.$ from the colonies), and all other weather variables were recorded at the Nappan (auto) weather station $\left(45.760^{\circ} \mathrm{N}, 64.241^{\circ} \mathrm{W}, \sim 17 \mathrm{~km}\right.$ from the colonies).
Although weather conditions were not specifically recorded at the colony or communal roosting sites, we assume that the weather conditions at these stations reflected those within the study area because of the strong spatial autocorrelation of these variables (Jones 1992, Nguyen et al. 2015, Malvaldi et al. 2017). We determined light levels based on the degree of cloud cover and moon phase on a given night by multiplying the daily moon phase $(\%)$ by 1 when cloud cover was $1,0.75$ when it was $2,0.5$ when it was 3 , and 0.25 when it was 4 . All data were downloaded from Environment Canada (http://climate.weather.gc.ca).

\section{Banding and tagging}

We captured 45 adults (19 male, 26 female) at TN and 23 adults (8 male, 15 female) at SE during late incubation using tube traps and mist nets. All birds were banded with a Canadian Wildlife Service aluminum band and sexed based on the presence of a brood patch or cloacal protuberance (Pyle 1997).

In most cases, we randomly attached Lotek NTQB-1 VHF transmitters to 31 selected birds at TN (16 male, 15 female) and 13 birds at SE ( 5 male, 8 female). However, we deviated from our random selection to tag both members of a pair (once the first individual was randomly tagged) for 10 nests at TN. By tagging both adults, we could determine if both parents left the nest on a given night. One member of a pair of tagged birds at TN lost its tag within $24 \mathrm{~h}$; therefore, we considered this nest as having only one tagged bird. Furthermore, in addition to the 10 nests with tagged pairs, we captured and tagged three adults from one nest at TN. Given that the true progenitors of this nest were unclear, data from these birds were excluded from our analysis.

The tags weighed $0.29 \mathrm{~g}(2.2 \pm 0.2 \%$ of the body weight of tagged individuals), which is below the $3 \%$ recommended maximum weight (Phillips et al. 2003). Tags had a minimal life expectancy ( $80 \%$ of total life expectancy) of $33 \mathrm{~d}$ with a burst rate of $10 \mathrm{~s}$. The tags were attached to trimmed feathers on the bird's lower mantle using a cyanoacrylate adhesive (Raim 1978). There have been no reports of ill-effects with this method of attachment, apart from minor local plumage damage (Sykes et al. 1990, NaefDaenzer et al. 2001, Schulz et al. 2001, Bowman et al. 2002, Dunn and Whittingham 2005, Mong and Sandercock 2007, Hansbauer and Pimentel 2008). Using this method, tags have a relatively short retention time (average 5-40 d; Sykes et al. 1990, Johnson et al. 1991, Bowman et al. 2002, Mong and Sandercock 2007) and thus were expected to drop off before fall migration.

\section{Automated telemetry array}

To monitor Bank Swallow movements to and from communal roost sites, we tracked the tagged birds with an array of 10 automated telemetry towers (Fig. 1). Each tower contained a data logging receiver (Sensorgnome; https://sensorgnome.org/), one omnidirectional or three nine-element Yagi antennas, and a power system including two car batteries and a solar panel. The receivers monitored each antenna continuously, and when a tagged swallow was within $\sim 0.5 \mathrm{~km}$ of an omnidirectional tower or $\sim 15 \mathrm{~km}$ of a Yagi tower (in the direction of the Yagi antennas only), its unique code and time of the detection were recorded (Taylor et al. 2017). Each tower was checked every three days to download data and insure the proper functioning of the equipment. 
Fig. 1. Map showing the locations of two Bank Swallow colonies (Tantramar North and Sackville Engineering), automated telemetry towers, and cattail wetlands. Red dots $=$ Bank Swallow colonies; blue lines and shading $=$ North towers and cattail wetlands, respectively; orange lines and shading = South towers and cattail wetlands, respectively. For each directional tower, the antenna directions are shown as $1-\mathrm{km}$ lines. The position of the two omnidirectional antennas erected at the colonies and their approximate detection range (up to 1 $\mathrm{km}$ ) are shown as red shaded circles around the colonies. The position and antenna directions of the directional tower School had simultaneous detections with the colony towers and is shown in red.

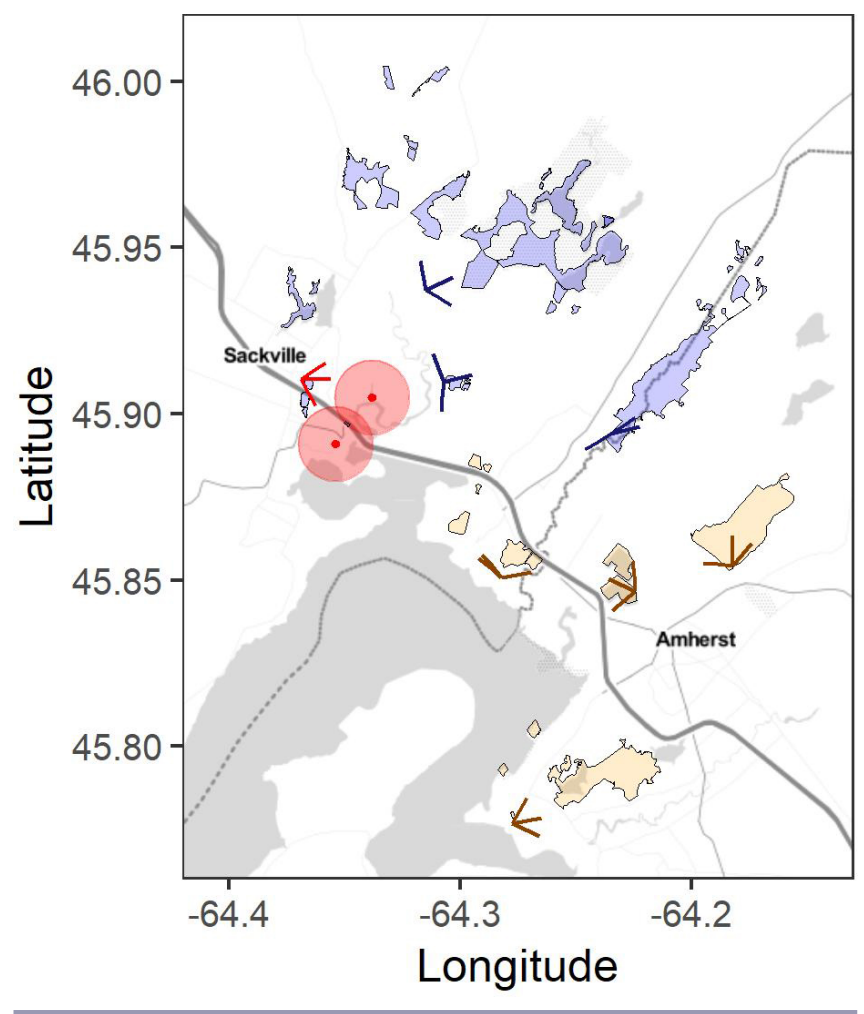

One tower equipped with omnidirectional antennas was erected at the top of the bank above each of the breeding colonies, and additional towers with Yagi antennas were placed in the open area surrounding the colonies and at potential communal roost sites (freshwater marshes within $20 \mathrm{~km}$ of the breeding colonies) to increase our ability to detect individuals flying to and from those roosts (Fig. 1). There were two clusters of marshes to the north and south of the colonies. Although each marsh was equipped with an automated tower (total of eight towers), it was difficult to determine exactly which marsh a tagged bird settled in for the night because the towers can detect individuals at some distance when in flight. Therefore, when a bird was detected at one or more of the three towers to the north of the colonies (Upper Tantramar, Tintamar Marsh, and Missaquash Marsh), it was considered to be roosting communally in the North, and when it was detected at one or more of the four southern towers (Amherst Marsh, Eddy St. Marsh, Beaubassin, Amherst Point), it was considered to be roosting communally in the South. The South and the North towers were positioned $12.3 \pm 2.6 \mathrm{~km}$ and $5.7 \pm 2.6 \mathrm{~km}$ from the colonies, respectively. One tower, School, was close $(\sim 2.5 \mathrm{~km})$ to the towers situated at the breeding colonies and had antennas pointing in the direction of the colonies. As a result, many birds were detected simultaneously at School and at the colony towers (70\% of detections at School were repeated at colony towers within the same minute). Therefore, birds detected at this tower were considered to be at their colonies. When Bank Swallow individuals were detected at the colony towers during the night, they were assumed to be roosting in their burrows. Although it is possible that they roosted elsewhere within this $\sim 0.5 \mathrm{~km}$ detection range of the omnidirectional antenna of the colony towers, field observations of tagged swallows in their burrows before sunrise suggest that they remained in their nests at night. Tagged individuals were detected at least once at sunrise or sunset on 880 of a possible 1001 nights $(88 \%$; counted as the sum of all days between the first and last detection of each tag). This suggests that the automated telemetry array was effective at identifying the roosting location of tagged Bank Swallow, despite gaps between towers, especially toward the west of the colonies.

\section{Communal roosting behavior}

Based on the distribution of the latest and earliest colony detections per day from birds known to be roosting, we found that birds departed and returned to the colony within 42 min of sunrise and sunset. Therefore, we classified detections into three categories: a bird was considered to have been detected at (1) sunset if it was recorded 42 min before or after sunset, (2) night if it was recorded between $42 \mathrm{~min}$ after sunset and $42 \mathrm{~min}$ before sunrise, and (3) sunrise if it was recorded $42 \mathrm{~min}$ before or after sunrise. If the bird was detected at night, we considered this location (either colony, North, or South) to be where the animal spent the night. If it was undetected at night but was detected either North or South at sunset and/or sunrise, it was considered to have roosted in one of those locations. If a bird was undetected at sunrise or sunset and only detected at the colony during the opposing twilight, its roosting location was considered ambiguous and it was omitted from the analysis (33 of 880; 4\%).

To determine the total amount of time spent away from the nest when roosting communally, we then determined the time of departure from and arrival at the colony by selecting the latest time of detection at the colony in the evening and the earliest time of detection at the colony in the morning. To control for changing day length, we then calculated the difference between these times and sunset and sunrise, with negative times being at night.

\section{Data analysis}

\section{Factors related to the likelihood of roosting communally}

To determine how the probability of roosting was related to biological and environmental factors, we fit generalized linear mixed models with a binary response variable (roosting communally or remaining at the colony) and random effects for individual and nest identification (ID). To select the best fitting model, we followed the information theoretic approach and compared a series of seven models using the Akaike Information Criterion (AIC; Burnham and Anderson 2002; MuMIn package, Barton 2019). These seven models included a null model with only 
the random effects, five models representing our hypotheses for the drivers and limiters of communal roosting (i.e., thermoregulatory needs of offspring, thermoregulatory needs of adults, predator avoidance, bank collapse, and increased parasite load or prospecting opportunities), and a full model that contained all biological and environmental variables combined. The model for the thermoregulatory needs for the offspring contained two environmental variables (temperature and relative humidity) and four biological variables (adult sex, nestling age, brood size, and whether the nest was active). In addition, this model included four interactions: (1) between sex and whether the nest was active, (2) between nestling age and whether the nest was active, (3) between nestling age and brood size, and (4) between nestling age and date. The first two interactions were included because they were hypothesized to coinfluence requirements for parents to be at the nest. The third was included because the thermoregulatory effects of brood size would increase as nestlings age and thus reduce the need for parents to be present at the nest. The fourth was included to determine if the relationship with nestling age was caused by changing parental care requirements alone or in combination with the progression of time. The model for the thermoregulatory needs of the adults contained three environmental variables: temperature, wind speed, and relative humidity. The models for predator avoidance and bank collapse included only the variables light and relative humidity, respectively. Finally, the model for parasite avoidance or prospecting future breeding sites included only date. We compared all seven models to select the best fit model(s) based on $\triangle \mathrm{AIC}$ (Burnham and Anderson 2002).

\section{Factors related to the timing of departure from and arrival at the colony}

We used a similar approach to assess the relative importance of biological and environmental factors on departure and arrival times at the colonies relative to sunset and sunrise. For these response variables, we fit linear mixed models with a random effect for individual. Nest ID was not included as a random effect because it caused singularity in some models. Again, we compared a series of models, including a null model, two models representing our hypotheses for the factors limiting the time spent away from the colony (thermoregulatory needs of offspring and thermoregulatory needs of adults), and a full model that contained all biological and environmental variables combined. Because date is known to affect the timing of communal roosting in other species (Smiddy et al. 2007), we included two versions of our model of the thermoregulatory needs of the adults with and without date, and a model of date on its own. The model for the thermoregulatory needs of offspring contained the same environmental variables (temperature, relative humidity), biological variables (adult sex, nestling age, brood size, and whether the nest was active) and four interactions (adult sex $\times$ active or inactive nest, nestling age $\times$ active or inactive nest, nestling age $\times$ brood size and nestling age $\times$ date). The model for the thermoregulatory needs of adults contained the same three environmental variables: temperature, wind speed, and relative humidity, to which we added the location of the communal roost (North or South). Again, we compared all six models to select the best fitting model(s) based on $\triangle \mathrm{AIC}$ (Burnham and Anderson 2002).
To improve convergence, we scaled and centered all numerical predictor variables in all models to have a mean of 0 and standard deviation of 1 (Zurr et al. 2013); all reported coefficients are expressed in those $Z$ scores. Means \pm 1 standard deviation are reported, and Pearson's correlation coefficients were calculated between the variables to verify that they were not collinear (all $r$ $<0.53$; Dormann et al. 2013) before running the models. We selected the best fitting model based on the lowest AIC; however, if competing models had $\triangle \mathrm{AIC}<2$, they were considered equivalent, and model averaging was used (Burnham and Anderson 2002). Below, we describe only the biological and environmental variables that had an effect on the model, i.e., those where the confidence intervals did not span zero.

\section{RESULTS}

From all nests monitored after the rainstorm event, we found that nests with one or two birds tagged had higher survival than those that were untagged (one: $71 \%, N=20$; two: $78 \%, N=9$; none: $59 \%, N=37$ ), suggesting that tagging had no detrimental effect on Bank Swallow nest success.

On average, tags were detected for $25 \pm 10 \mathrm{~d}$. During this time, we identified 593 (of a possible 880 occasions) when adults roosted communally (Table 1). Thirty-nine of 40 tagged birds roosted communally at least once, and 34 remained at their colony at least once. There was considerable individual variability, with Bank Swallow individuals roosting communally on average $70 \pm 25 \%$ of the nights. Across the period of our study, both males and females used communal roost sites on the same proportion of nights $\left(t_{36}=0.36, P=0.72\right.$ ), although the sexes differed in when they roosted communally as described in more detail below. On $90 \%(535 / 593)$ of occasions, birds roosted at sites in the North (Table 1). Despite the overall preference for the North, a considerable degree of roost switching was observed, with 14 of the 39 birds that roosted using both North and South communal roosts. Birds that roosted in the North or South were last detected at the colony $7.3 \pm 11.9 \mathrm{~min}$ after sunset and were first detected in the morning $11.5 \pm 12.4 \mathrm{~min}$ after sunrise.

In eight of the nine pairs in which both adults were tagged, both adults roosted communally on the same night at least once (Fig. 2). Of these eight pairs, six successfully fledged nestlings. These successful pairs roosted simultaneously 3-13 times while their nests were active, starting when their young were $11-14 \mathrm{~d}$ old. The

Table 1. Summary of detected roosting locations out of the total possible roosting locations.

\begin{tabular}{lccc}
\hline \hline Roost & $\begin{array}{c}\text { Number of Bank } \\
\text { Swallows }\end{array}$ & $\begin{array}{c}\text { Number of } \\
\text { nights }^{\ddagger}\end{array}$ & $\begin{array}{c}\text { Total roosting } \\
\text { occasions }^{\S}\end{array}$ \\
\hline North & 38 & 48 & 535 \\
South & 15 & 30 & 58 \\
Colony & 34 & 59 & 254 \\
Unknown location & 21 & 20 & 33 \\
Total possible & 40 & 63 & 1001 \\
\hline${ }^{\dagger}$ Number of Bank Swallow individuals that used this location at least \\
once. \\
${ }^{\ddagger}$ Nights with at least one bird roosting at this location. \\
${ }^{\S}$ Total number of times roost site was used by all individuals.
\end{tabular}


Table 2. Model comparison for the effects of biological and environmental factors on the likelihood of Bank Swallow roosting. The best-fitting model is indicated in bold font. All models listed also included random effects for individual and nest ID. The Akaike Information Criterion (AIC) of the top model was 1337.1.

\begin{tabular}{|c|c|c|c|c|c|}
\hline Model description & Fixed parameters & $\mathrm{df}^{\dagger}$ & log likelihood & $\Delta \mathrm{AIC}$ & $w_{\mathrm{i}}$ \\
\hline Full model & $\begin{array}{l}\text { temperature }+ \text { wind speed }+ \text { relative humidity }+ \text { light }+ \text { nestling } \\
\text { age } \times \text { active/inactive nest }+ \text { date } \times \text { nestling age }+ \text { sex } \times \text { active } / \\
\text { inactive nest }+ \text { nestling age } \times \text { brood size }\end{array}$ & 16 & -651.6 & 0.0 & 1.0 \\
\hline Offspring thermoregulation & $\begin{array}{l}\text { temperature }+ \text { relative humidity }+ \text { nestling age } \times \text { active/inactive } \\
\text { nest }+ \text { date } \times \text { nestling age }+ \text { sex } \times \text { active/inactive nest }+ \text { nestling } \\
\text { age } \times \text { brood size }\end{array}$ & 14 & -671.7 & 36.4 & 0.0 \\
\hline Parasite avoidance or prospecting & date & 4 & -779.6 & 232.1 & 0.0 \\
\hline Predator avoidance & light & 4 & -784.9 & 242.6 & 0.0 \\
\hline Adult thermoregulation & temperature + wind + relative humidity & 6 & -799.0 & 274.9 & 0.0 \\
\hline Colony collapse & relative humidity & 4 & -802.2 & 277.3 & 0.0 \\
\hline Null & none & 3 & -807.0 & 286.8 & 0.0 \\
\hline
\end{tabular}

Fig. 2. Proportion of nights during which parents with and without active nests spent their time at the colony or at a commual roost. Colony $=$ both parents remained at the colony, comm. roost $=$ both parents roosted communally, and separated $=$ one parent roosted communally while the other remained at the colony. The boxplots represent quartiles and the whiskers indicate the highest and lowest values within 1.5 times the interquartile range.

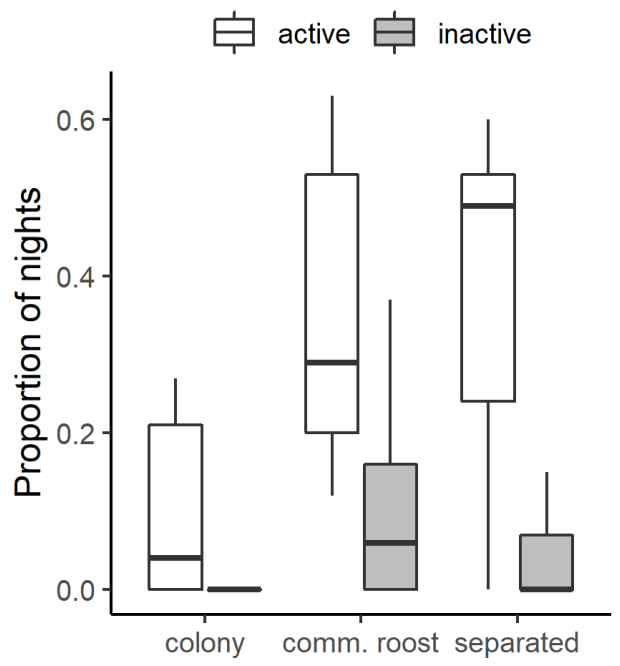

two unsuccessful pairs failed at the egg stage, and then both adults roosted simultaneously every night that they continued to be detected.

\section{Factors related to the likelihood of roosting communally}

The best supported model was the full model (Tables 2 and 3). Although females were more likely to roost communally than males in inactive nests, they were less likely to roost communally when the nest was active (Fig. 3A). The likelihood of roosting communally increased with nestling age in active nests, but decreased with nestling age in inactive nests (Fig. 3B). Moreover, although the probability of roosting decreased with nestling age overall, this decrease was smaller in nests with larger broods (Fig. 3C). Finally, the likelihood of roosting communally decreased more rapidly with nestling age as the season progressed (Fig. 3D). The simple effects of the environmental factors suggest that the likelihood of roosting communally decreased with increasing relative humidity and light levels.

\section{Factors related to the timing of departure from and arrival times at the colony}

Environmental factors were related to the timing of departure from and arrival at the colony and thus the amount of time nests were left unattended. The best supported models for departure and arrival times were adult thermoregulation and date, respectively. Individuals departed later relative to sunset when relative humidity and temperatures were low and arrived at the colonies later relative to sunrise as the season progressed (Tables 4 and 5).

\section{DISCUSSION}

Thirty-nine of the 40 breeding Bank Swallow individuals that we tracked used communal roosts sites at least once, confirming that adults will roost communally away from their active nests during the breeding season. Indeed, our results suggest that this behavior is common for both males and females, despite strong individual variability, as previously demonstrated by Falconer et al. (2016). We also found strong correlations between the likelihood of roosting communally and time spent away from the colony (regulated by the departure and arrival time at the colony), as well as biological factors such as sex, nestling age, brood size, and whether the nest was active, and environmental factors such as relative humidity, temperature, light, and date. Although some of these relationships can be explained by the thermoregulatory needs of offspring and adults (e.g., relationships with biological factors and weather conditions), others appear to be associated with predator avoidance (e.g., light) and avoidance of ectoparasites at the colonies or prospecting new breeding areas (e.g., date) 
Table 3. Model output for the effects of environmental and biological factors on the likelihood of Bank Swallow roosting, including the estimate, standard error (SE) and 95\% confidence intervals (lower confidence limit [LCL] and upper confidence limit [UCL]). Variables for which the confidence interval does not span 0 are indicated in bold font. Continuous variables are expressed as $Z$ scores.

\begin{tabular}{|c|c|c|c|c|c|c|}
\hline \multirow[t]{2}{*}{ Variables } & \multicolumn{4}{|c|}{ Fixed effects } & \multicolumn{2}{|c|}{ Random effects } \\
\hline & Estimate & SE & $\mathrm{LCL}$ & UCL & Variance & $\begin{array}{l}\text { Standard } \\
\text { deviation }\end{array}$ \\
\hline Intercept & 1.11 & 1.02 & -0.90 & 3.11 & & \\
\hline Sex (female) & 2.61 & 0.76 & 1.12 & 4.10 & & \\
\hline Nestling age & -0.87 & 0.31 & -1.47 & -0.27 & & \\
\hline Brood size & -0.18 & 0.27 & -0.70 & 0.34 & & \\
\hline Active/inactive nest (active) & -0.33 & 0.38 & -1.08 & 0.41 & & \\
\hline Temperature & 0.09 & 0.05 & -0.01 & 0.18 & & \\
\hline Wind speed & -0.11 & 0.09 & -0.28 & 0.05 & & \\
\hline Relative humidity & -0.35 & 0.08 & -0.52 & -0.19 & & \\
\hline Light & -0.50 & 0.09 & -0.69 & -0.32 & & \\
\hline Date & 0.60 & 0.33 & -0.05 & 1.24 & & \\
\hline Sex (female) $\times$ active/inactive nest (active) & -3.93 & 0.52 & -4.94 & -2.92 & & \\
\hline Nestling age $\times$ active/inactive nest (active) & 1.15 & 0.19 & 0.78 & 1.51 & & \\
\hline Brood size $\times$ nestling age & 0.53 & 0.10 & 0.34 & 0.71 & & \\
\hline Nestling age $\times$ date & -0.49 & 0.10 & -0.68 & -0.29 & & \\
\hline Individual & & & & & 2.55 & 1.60 \\
\hline Nest & & & & & 0.01 & 0.10 \\
\hline
\end{tabular}

Fig. 3. Predicted probabilities of roosting communally according to four statistical factor interactions. (A) Sex $\times$ nest state (active or inactive), (B) nestling age $\times$ nest state, $(\mathrm{C})$ nestling age $\times$ brood size, and (D) nestling age $\times$ date. All continuous variables (e.g., brood size and date) are expressed as $\mathrm{Z}$ scores (i.e., scaled and centered). In (B-D), the vertical black line indicates the initiation of incubation. Predicted $\mathrm{Z}$ scores and their 95\% confidence intervals (CI) are represented as points and error bars for the interaction between two categorical variables $(\mathrm{A})$ or as lines and shaded areas for the interaction with at least one continuous variable (B-D). To represent the interaction between two continuous variables, the $\mathrm{Z}$ scores and $95 \% \mathrm{CI}$ for the mean \pm standard deviation of the $y$-axis variable are shown.

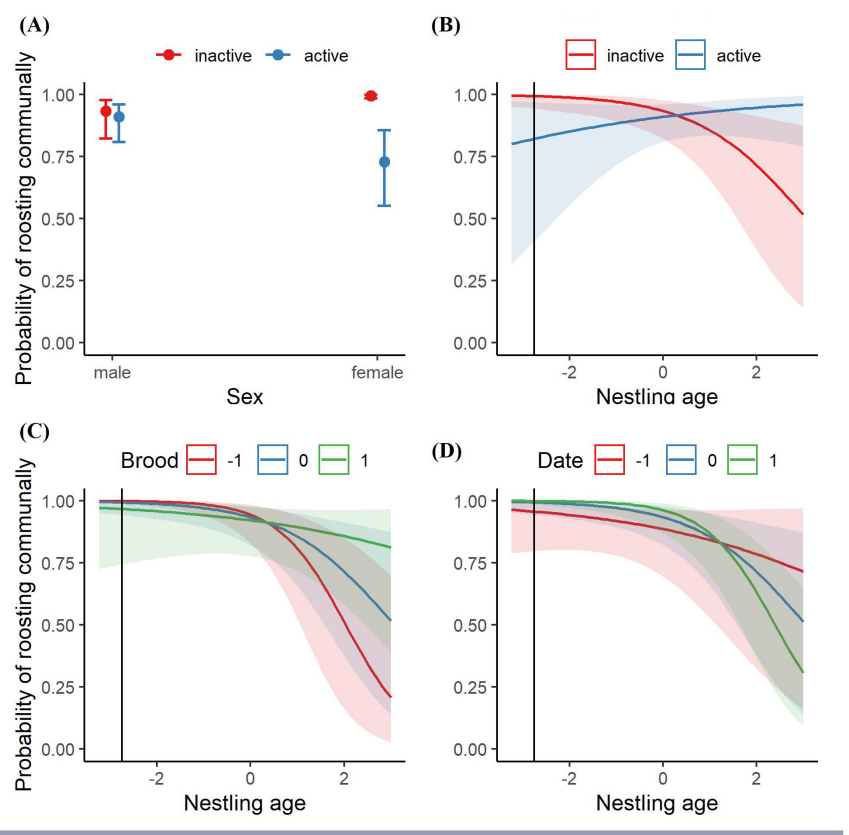

Our results support the hypothesis that communal roosting during the breeding season is limited by the thermoregulatory needs of the young. Offspring developing under variable temperatures suffer from reduced growth rates and survival (Ardia 2013). In birds, parents with altricial offspring use incubation and brooding to buffer these differences in temperature, especially during late incubation (Cooper and Voss 2013) and the period right after hatching, when offspring are partially ectothermic (7-10 d post hatch in Bank Swallow; Dunn 1975, Marsh 1979, Marsh and Wickler 1982, Sirsat et al. 2016). Roosting communally during the breeding season conflicts with nighttime incubation and brooding; therefore, adults may only roost communally when the benefits of this behavior outweigh potential thermoregulatory costs to the offspring. Like most passerines, Bank Swallow females spend more time incubating and brooding than do males (Petersen 1955), which may explain why, like Falconer et al. (2016), we found that females roosted communally less often than did males while their nests were active. This result may also explain the bias toward nonbreeding birds and males using communal roosts during the breeding season in other species (Meanly 1965, Hill and Cresswell 1997). Similarly, we found that both sexes of Bank Swallow were less likely to roost communally when nestlings were young and required frequent brooding than when they were older. We also found that the rate of roosting communally decreased more rapidly with nestling age in nests with smaller broods, which are less thermally stable than large broods (Dunn 1975). This result differs from that of Falconer et al. (2016), who found no relationship between the likelihood of roosting communally and brood size, although this may be because nestling age was not included in the models. Finally, we found that the likelihood of roosting communally decreased with relative humidity. In poor weather conditions, the thermoregulatory needs of offspring are high, and birds increase the time spent incubating and brooding to prevent detrimental effects (Coe et al. 2015). Therefore, adults may have avoided 
Table 4. Model comparison for the effects of biological and environmental factors on Bank Swallow relative departure time moving from the colony to the roosts in the evening, and arrival time moving from the roost to the colony in the morning. The best-fitting model is indicated in bold font. All models included random effects for individual. The Akaike Information Critera (AICs) for the top models were -189.3 and -146.4 for departure and arrival, respectively.

\begin{tabular}{|c|c|c|c|c|c|}
\hline Model description & Model parameters & $\mathrm{df}^{\dagger}$ & $\begin{array}{c}\log \\
\text { Likelihood }\end{array}$ & $\triangle \mathrm{AIC}$ & $w_{\mathrm{i}}^{*}$ \\
\hline \multicolumn{6}{|l|}{ Departure from colony in the evening } \\
\hline Adult thermoregulation & temperature + wind speed + relative humidity + North/South roost & 7 & 101.8 & 0.0 & 0.96 \\
\hline Adult thermoregulation with date & $\begin{array}{l}\text { temperature }+ \text { wind speed }+ \text { relative humidity }+ \text { North/South } \\
\text { roost }+ \text { date }\end{array}$ & 8 & 99.7 & 6.32 & 0.04 \\
\hline Offspring thermoregulation & $\begin{array}{l}\text { temperature }+ \text { relative humidity }+ \text { nestling age } \times \text { active/inactive } \\
\text { nest }+ \text { date } \times \text { nestling age }+ \text { sex } \times \text { active/inactive nest }+ \text { nestling } \\
\text { age } \times \text { brood size }\end{array}$ & 14 & 92.2 & 33.97 & 0.00 \\
\hline Null & none & 3 & 78.2 & 39.03 & 0.00 \\
\hline Date & date & 4 & 74.7 & 48.01 & 0.00 \\
\hline Full model & $\begin{array}{l}\text { temperature }+ \text { wind speed }+ \text { relative humidity }+ \text { North } / \text { South } \\
\text { roost }+ \text { nestling age } \times \text { active/inactive nest }+ \text { date } \times \text { nestling age } \\
+ \text { sex } \times \text { active/inactive nest }+ \text { nestling age } \times \text { brood size }\end{array}$ & 16 & 86.9 & 48.89 & 0.00 \\
\hline \multicolumn{6}{|l|}{ Arrival at colony in the morning } \\
\hline Date & date & 4 & 77.2 & 0.0 & 0.83 \\
\hline Adult thermoregulation with date & $\begin{array}{l}\text { temperature }+ \text { wind speed }+ \text { relative humidity }+ \text { North/South } \\
\text { roost }+ \text { date }\end{array}$ & 8 & 79.6 & 3.48 & 0.15 \\
\hline Adult thermoregulation & $\begin{array}{l}\text { temperature }+ \text { wind speed }+ \text { relative humidity }+ \text { North/South } \\
\text { roost }\end{array}$ & 7 & 76.7 & 7.15 & 0.02 \\
\hline Null & none & 3 & 70.6 & 11.30 & 0.00 \\
\hline Offspring thermoregulation & $\begin{array}{l}\text { temperature }+ \text { relative humidity }+ \text { nestling age } \times \text { active/inactive } \\
\text { nest }+ \text { date } \times \text { nestling age }+ \text { sex } \times \text { active/inactive nest }+ \text { nestling } \\
\text { age } \times \text { brood size }\end{array}$ & 14 & 60.4 & 54.67 & 0.00 \\
\hline Full model & temperature + wind speed + date & 16 & 61.74 & 56.2 & 0.01 \\
\hline
\end{tabular}

roosting communally or spending a long time away from the colony in inclement weather. Interestingly, temperature did not appear to relate to the likelihood of roosting communally. Bank Swallow burrows are well insulated and may provide more protection from temperature changes than from changes in relative humidity (Ellis 1982). Overall, the thermoregulatory needs of offspring can explain why the Bank Swallow reduces communal roosting and time spent away from the colony when the nest is active.

The likelihood of roosting communally and the total time spent away from the colony may also relate to the thermoregulatory needs of the adults, especially when the nest is inactive. We found that Bank Swallow individuals were less likely to use communal roost sites in wet weather, i.e., when relative humidity was high, than in dry weather. This result may be explained by the thermoregulatory protection provided by the nest vs. the roost and associated costs of travel during inclement weather. Although communal roosts provide thermal protection through social clustering and dense vegetation (Eiserer 1984), burrows may provide a stronger buffer from inclement weather for this species. For example, at our study sites, burrows were, on average, 50.72 $\pm 8.94 \mathrm{~cm}$ deep (S. Saldanha, unpublished data), and previous work shows that during ambient temperatures of $2.4-46.7^{\circ} \mathrm{C}$, burrow temperatures ranged from $15.0-24.9^{\circ} \mathrm{C}$ (Ellis 1982). Therefore, adults may be less likely to leave or spend long periods away from their nests during wet weather (White et al. 1978, Ellis 1982, Lill and Fell 2007). The fact that birds occasionally remained at the colony when their nest was inactive also supports this hypothesis.
Furthermore, the energetic costs of travelling during poor weather conditions may also explain why Bank Swallow individuals remain in their nest at night more frequently and spend less time away from the colony in bad weather. Many studies have found that birds and bats avoid travelling for both foraging and migration in poor weather conditions (Anthony et al. 1981, Evans and Bouwman 2000, Erni et al. 2002). Together with the thermoregulatory needs of offspring, the thermoregulatory needs of adults may therefore influence whether Bank Swallow individuals commute to communal roosts and the total time they spend away from the colony when roosting communally, especially when the nests are inactive.

The likelihood of roosting communally may also be associated with predation risk. We found that the likelihood of roosting decreased with increasing ambient light. Species with nocturnal predators are known to reduce their activity on bright nights (Brooke and Prince 1991, Lang et al. 2006). For the Bank Swallow, predation risk may differ between the colony and communal roost sites. In the nest, the Bank Swallow is depredated by snakes and nocturnal olfactory predators such as raccoons (Procyon lotor), skunks (Mephitis mephitis), and red foxes (Vulpes vulpes; Stoner 1936, Plummer 1977, Hjertaas 1984, Ghent 2001 Falconer et al. 2016, Burke 2017). In our study, nocturnal predators depredated one nest with a tagged adult. Because the Bank Swallow has few defences against these predators (mobbing mostly occurs with diurnal avian predators; Hoogland and Sherman 1976, Plummer 1977), communal roosting may be a way of avoiding predation. However, communal roosts can also attract specialized predators. 
Table 5. Model output for the effects of environmental and biological factors on the timing of Bank Swallow departure from and arrival at the colony for roosting, including the estimate, standard error (SE), and 95\% confidence intervals (lower confidence limit [LCL] and upper confidence limit [UCL]). Variables for which the confidence interval does not span 0 are indicated in bold font. All continuous variables are expressed as $Z$ scores.

\begin{tabular}{|c|c|c|c|c|c|c|}
\hline \multirow[b]{2}{*}{ Model and variables } & \multicolumn{4}{|c|}{ Fixed effects } & \multicolumn{2}{|c|}{ Random effects } \\
\hline & Estimate & SE & $\mathrm{LCL}$ & UCL & Variance & $\begin{array}{l}\text { Standard } \\
\text { deviation }\end{array}$ \\
\hline \multicolumn{7}{|c|}{ Departure from colony in the evening } \\
\hline Intercept & -0.12 & 0.01 & -0.15 & -0.10 & & \\
\hline Temperature & 0.02 & 0.01 & 0.00 & 0.04 & & \\
\hline Wind speed & -0.01 & 0.01 & -0.03 & 0.00 & & \\
\hline Relative humidity & 0.08 & 0.01 & 0.06 & 0.10 & & \\
\hline Roost (South) & 0.01 & 0.05 & -0.10 & 0.12 & & \\
\hline Individual & & & & & 0.00 & 0.05 \\
\hline \multicolumn{7}{|c|}{ Arrival at colony in the morning } \\
\hline Intercept & 0.19 & 0.02 & 0.17 & 0.23 & & \\
\hline Date & 0.06 & 0.01 & 0.03 & 0.08 & & \\
\hline Individual & & & & & 0.01 & 0.08 \\
\hline
\end{tabular}

For example, the African Hobby (Falco cuvieri) times its presence and behavior in conjunction with the arrival and departure of swallows from communal roosts (Bijlsma and van den Brink 2005). Therefore, on bright nights, the predation risk at communal roosts may be higher than at the colony. Further studies of the relative predation pressures at colonies and communal roosts are needed to measure whether predator avoidance is an evolutionary driver for communal roosting behavior.

We found that adults remained at the nests on humid nights despite the increased risk of bank collapse in heavy rain and associated threats to survival (see also Burke 2017). Therefore, the thermoregulatory benefits of remaining at the colony during humid nights may outweigh the risk of bank collapse or perhaps relative humidity alone is not a strong predictor of rainfall severe enough to cause bank collapse. Further studies investigating Bank Swallow roosting behavior during severe rainfall events may aid in clarifying this distinction.

Finally, we found that Bank Swallow individuals roosted communally more often as the season progressed while the nests were active. Although this behavior may be driven by reduced thermoregulatory needs of the offspring, other factors such as parasite avoidance and prospecting opportunities may also play a role. As the breeding season progresses, ectoparasite loads increase in swallow colonies (Burke 2017), affecting both adults and young (Szép and Møller 2000). In the Cliff Swallow (Petrochelidon pyrrhonota), ectoparasites have even been shown to shorten the breeding season, with adults departing for migration earlier when infection levels are high than when they are low (Brown and Brown 2015). Prospecting future breeding habitat may also drive this behavior near the end of the breeding season. Consistent with Falconer et al. (2016), we found that although most Bank Swallow individuals depart from their colonies to roost communally before sunset, they only return from communal roosts after sunrise, and this time becomes later as the season progresses. This behavior gives them time in the morning to forage and prospect conspecific reproductive success before returning to the colony. Indeed, Brown et al. (2000) found that Cliff Swallow individuals prospect conspecific colonies near the end of the breeding season. Additional experimental studies of ectoparasite levels and added spatial precision of manual tracking along the commutes to and from communal roost sites are needed to explore the relative importance of these variables as drivers for communal roosting.

Although the observed effects of biological and environmental factors on the likelihood of roosting communally support several of our hypotheses, much of the variance in our models remains unexplained. This result suggests that additional drivers for this behavior may be at play. For example, individuals may be benefitting from additional feeding opportunities while traveling and upon arrival at communal roost sites, as suggested by Falconer et al. (2016). Although the Bank Swallow is a solely diurnal feeder, individuals roost communally in wetlands that are known to harbor high aerial insect abundance and may take advantage of these sites (King and Wrubleski 1998). Further studies using fine-scale manual tracking are necessary to measure the importance of this potential benefit. By combining the use of automated telemetry systems and fine-scale manual tracking, researchers can benefit from the respective advantages of continuous tracking and accuracy. This strategy may be key in future studies of the drivers of communal roosting in the Bank Swallow or those examining whether this behavior occurs in others species during the breeding season.

The results of our study are consistent with the results of a previous study (Falconer et al. 2016) suggesting that communal roosting is a prominent behavior in breeding Bank Swallow, despite restrictions associated with parental care and thermoregulation. Therefore, identifying communal roost sites and determining how and when they are used throughout the breeding season may play an important role in fulfilling the requirement of the Species At Risk Act to designate critical habitat and recovery actions for this threatened species. Because communal roosting occurs outside of diurnal activity centers, it may be necessary to protect the wetland habitats where this behavior occurs, in addition to Bank Swallow nesting habitat. Further studies identifying communal roost site characteristics and their spatiotemporal consistency are needed to understand fully the habitat use associated with this behavior in the Bank Swallow. 
Avian Conservation and Ecology 14(2): 21

http://www.ace-eco.org/vol14/iss2/art21/

Responses to this article can be read online at:

http://www.ace-eco.org/issues/responses.php/1490

\begin{abstract}
Acknowledgments:
We thank A. McKeen and B. Crosby for collecting and compiling data on Bank Swallow roosting behavior. Many thanks to the numerous other field-staff and volunteers that helped with roost and Bank Swallow breeding success counts, notably L. Burke, M. Courtenay, D. Farrar, and staff from Environment and Climate Change Canada and Ducks Unlimited Canada. We also thank private landowners, Acadia University, Ducks Unlimited Canada, and Environment and Climate Change Canada for permitting access to their properties for field research. We give special thanks to $P$. Thomas and B. Whittam at Environment and Climate Change Canada for supporting this work and to M. Falconer for early guidance on the project. Funding was provided by (in alphabetical order) Environment and Climate Change Canada, the Natural Sciences and Engineering Research Council of Canada, New Brunswick Wildlife Trust Fund, Nova Scotia Habitat Conservation Fund, and Wildlife Preservation Canada.
\end{abstract}

\section{LITERATURE CITED}

Alonso, J. A., J. C. Alonso, and J. P. Veiga. 1985. The influence of moonlight on the timing of roosting flights in common cranes Grus grus. Ornis Scandinavica 16(4):314-318. https://doi. org/10.2307/3676696

Anthony, E. L. P., M. H. Stack, and T. H. Kunz. 1981. Night roosting and the nocturnal time budget of the little brown bat, Myotis lucifugus: effects of reproductive status, prey density, and environmental conditions. Oecologia 51(2):151-156. https://doi. org/10.1007/BF00540593

Ardia, D. R. 2013. The effects of nestbox thermal environment on fledging success and haematocrit in tree swallows. Avian Biology Research 6(2):99-103. https://doi.org/10.3184/175815513X13609528031394

Barton, K. 2019. Package 'MuMIn'. Version 1.43.10. [online] URL: https://CRAN.R-project.org/package=MuMIn

Beauchamp, G. 1999. The evolution of communal roosting in birds: origin and secondary losses. Behavioral Ecology 10 (6):675-687. https://doi.org/10.1093/beheco/10.6.675

Bijlsma, R. G., and B. van den Brink. 2005. A Barn Swallow Hirundo rustica roost under attack: timing and risks in the presence of African hobbies Falco cuvierii. Ardea 93(1):37-48.

Biro, D., D. J. T. Sumpter, J. Meade, and T. Guilford. 2006. From compromise to leadership in pigeon homing. Current Biology 16 (21):2123-2128. https://doi.org/10.1016/j.cub.2006.08.087

Blanco, G. 1996. Population dynamics and communal roosting of white storks foraging at a Spanish refuse dump. Colonial Waterbirds 19(2):273-276. https://doi.org/10.2307/1521871

Blanco, G., and J. L. Tella. 1999. Temporal, spatial and social segregation of red-billed choughs between two types of communal roost: a role for mating and territory acquisition. Animal Behavior 57(6):1219-1227. https://doi.org/10.1006/ anbe.1999.1103

Boesch, C. 1994. Cooperative hunting in wild chimpanzees. Animal Behavior 48(3):653-667. https://doi.org/10.1006/anbe.1994.1285

Bonduriansky, R., and R. J. Brooks. 1999. Why do male antler flies (Protopiophila litigata) fight? The role of male combat in the structure of mating aggregations on moose antlers. Ethology Ecology and Evolution 11(3):287-301. https://doi.

org/10.1080/08927014.1999.9522829

Bowman, J., M. C. Wallace, W. B. Ballard, J. H. Brunjes IV, M. S. Miller, and J. M. Hellman. 2002. Evaluation of two techniques for attaching radio transmitters to turkey poults. Journal of Field Ornithology 73(3):276-280. https://doi.org/10.1648/0273-8570-73.3.276

Brooke, M. D. L., and P. A. Prince. 1991. Nocturnality in seabirds. Proceedings of the International Ornithological Congress 20:1113-1121.

Brown, C. R., and M. B. Brown. 2015. Ectoparasitism shortens the breeding season in a colonial bird. Royal Society Open Science 2:140508. https://doi.org/10.1098/rsos. 140508

Brown, C. R., M. B. Brown, and E. Danchin. 2000. Breeding habitat selection in cliff swallows: the effect of conspecific reproductive success on colony choice. Journal of Animal Ecology 69(1):133-142. https://doi.org/10.1046/j.1365-2656.2000.00382.x

Burke, T. 2017. Bank Swallow (Riparia riparia) breeding in aggregate pits and natural habitats. Thesis. Trent University, Peterborough, Canada. [online] URL: http://digitalcollections. trentu.ca/objects/etd-553

Burnham, K. P., and D. R. Anderson. 2002. Model selection and multimodel inference: a practical information-theoretic approach. Second edition. Springer, New York, New York, USA. http://dx. doi.org/10.1007/b97636

Caccamise, D. F., L. M. Reed, J. Romanowski, and P. C. Stouffer. 1997. Roosting behavior and group territoriality in American crows. The Auk 114(4):628-637. https://doi.org/10.2307/4089282

Coe, B. H., M. L. Beck, S. Y. Chin, C. M. B. Jachowski, and W. A. Hopkins. 2015. Local variation in weather conditions influences incubation behavior and temperature in a passerine bird. Journal of Avian Biology 46(4):385-394. https://doi. org/10.1111/jav.00581

Cooper, C. B., and M. A. Voss. 2013. Avian incubation patterns reflect temporal changes in developing clutches. Plos One 8(6): e65521. https://doi.org/10.1371/journal.pone.0065521

Cougill, S., and S. J. Marsden. 2004. Variability in roost size in an Amazona parrot: implications for roost monitoring. Journal of Field Ornithology 75(1):67-73. https://doi.org/10.1648/0273-8570-75.1.67

Curnutt, J. L. 1992. Dynamics of a year-round communal roost of bald eagles. Wilson Bulletin 104(3):536-540. [online] URL: https://sora.unm.edu/sites/default/files/journals/wilson/v104n03/ p0536-p0540.pdf

Dormann, C. F., J. Elith, S. Bacher, C. Buchmann, G. Carl, G. Carré, J. R. G. Marquéz, B. Gruber, B. Lafourcade, P. J. Leitão, 
T. Münkemüller, C. McClean, P. E. Osborne, B. Reineking, B. Schröder, A. K. Skidmore, D. Zurell, and S. Lautenbach. 2013. Collinearity: a review of methods to deal with it and a simulation study evaluating their performance. Ecography 36(1):27-46. https://doi.org/10.1111/j.1600-0587.2012.07348.x

Dunn, E. H. 1975. The timing of endothermy in the development of altricial birds. The Condor 77(3):288-293. https://doi. org/10.2307/1366224

Dunn, P. O., and L. A. Whittingham. 2005. Radio-tracking of female tree swallows prior to egg-laying. Journal of Field Ornithology 76(3):259-263. https://doi.org/10.1648/0273-8570-76.3.259

Eiserer, L. A. 1984. Communal roosting in birds. Bird Behavior 5 (2-3):61-80. [online] URL: https://www.ingentaconnect.com/ contentone/cog/bb/1984/00000005/F0020002/art00001?crawler=true

Ellis, J. H. 1982. The thermal nest environment and parental behavior of a burrowing bird, the Bank Swallow. The Condor 84 (4):441-443 https://doi.org/10.2307/1367451

Erni, B., F. Liechti, L. G. Underhill, and B. Bruderer. 2002. Wind and rain govern the intensity of nocturnal bird migration in central Europe - a log-linear regression analysis. Ardea 90 (1):155-166.

Evans, S. W., and H. Bouwman. 2000. The influence of mist and rain on the reproductive success of the Blue Swallow Hirundo atrocaerulea (1995-96). Ostrich 71(1-2):83-86. https://doi. org/10.1080/00306525.2000.9639875

Falconer, C. M., G. W. Mitchell, P. D. Taylor, and D. C. Tozer. 2016. Prevalence of disjunct roosting in nesting bank swallows (Riparia riparia). Wilson Journal of Ornithology 128(2):429-434. https://doi.org/10.1676/1559-4491-128.2.429

Garrison, B. A. 1999. Bank Swallow (Riparia riparia). Version 2.0. In A. F. Poole and F. B. Gill, editors. The birds of North America. Cornell Lab of Ornithology, Ithaca, New York, USA. https://doi.org/10.2173/bna.414

Ghent, A. W. 2001. Importance of a low talus in location of Bank Swallow (Riparia riparia) colonies. American Midland Naturalist 146:447-449.

Hansbauer, M. M., and R. G. Pimentel. 2008. A comparison of five techniques for attaching radio-transmitters to tropical passerine birds. Revista Brasileira de Ornitologia 16(2):131-136. [online] URL: http://www.revbrasilornitol.com.br/BJO/article/ view/0332/pdf_543

Hill, I. F., and B. Cresswell. 1997. The use of a communal summer roost by radio-tagged blackbirds Turdus merula. Bird Study 44 (1):114-116. https://doi.org/10.1080/00063659709461044

Hjertaas, D. G. 1984. Colony site selection in bank swallows. Thesis. University of Saskatchewan, Saskatoon, Canada. [online] URL: https://harvest.usask.ca/handle/10388/etd-09302009-144952

Hoogland, J. L., and P. W. Sherman. 1976. Advantages and disadvantages of Bank Swallow (Riparia riparia) coloniality. Ecological Monographs 46:33-58. https://doi.org/10.2307/1942393

Johnson, G. D., J. L. Pebworth, and H. O. Krueger. 1991. Retention of transmitters attached to passerines using a glue-on technique. Journal of Field Ornithology 62(4):486-491. [online] URL: https://sora.unm.edu/sites/default/files/journals/jfo/v062n04/ p0486-p0491.pdf

Jones, P. A. 1992. Cloud-cover distributions and correlations. Journal of Applied Meteorology 31:732-741. https://doi. org/10.1175/1520-0450(1992)031<0732:CCDAC >2.0.CO;2

King, R. S., and D. A. Wrubleski. 1998. Spatial and diel availability of flying insects as potential duckling food in prairie wetlands. Wetlands 18(1):100-114. https://doi.org/10.1007/ BF03161448

Krantz, P. E., and S. A. Gauthreaux Jr. 1975. Solar radiation, light intensity, and roosting behavior in birds. Wilson Bulletin 87 (1):91-95. [online] URL: https://www.jstor.org/stable/4160579

Krause, J., and G. D. Ruxton. 2002. Living in groups. Oxford University Press, Oxford, UK.

Lack, D. 1968. Ecological adaptations for breeding in birds. Methuen, London, UK.

Lambertucci, S. A., and A. Ruggiero. 2013. Cliffs used as communal roosts by Andean condors protect the birds from weather and predators. Plos One 8(6):e67304. https://doi. org/10.1371/journal.pone.0067304

Lang, A. B., E. K. V. Kalko, H. Römer, C. Bockholdt, and D. K. N. Dechmann. 2006. Activity levels of bats and katydids in relation to the lunar cycle. Oecologia 146(4):659-666. https://doi. org/10.1007/s00442-005-0131-3

Laughlin, A. J., D. R. Sheldon, D. W. Winkler, and C. M. Taylor. 2014. Behavioral drivers of communal roosting in a songbird: a combined theoretical and empirical approach. Behavioral Ecology 25(4):734-743. https://doi.org/10.1093/beheco/aru044

Lill, A., and P. J. Fell. 2007. Microclimate of nesting burrows of the Rainbow Bee-eater. Emu 107(2):108-114. https://doi. org/10.1071/MU06046

Malvaldi, A., S. Weiss, D. Infield, J. Browell, P. Leahy, and A. M. Foley. 2017. A spatial and temporal correlation analysis of aggregate wind power in an ideally interconnected Europe. Wind Energy 20(8):1315-1329. https://doi.org/10.1002/we.2095

Marsh, R. L. 1979. Development of endothermy in nestling bank swallows (Riparia riparia). Physiological Zoology 52:340-353. https://doi.org/10.1086/physzool.52.3.30155755

Marsh, R. L., and S. J. Wickler. 1982. The role of muscle development in the transition to endothermy in nestling bank swallows, Riparia riparia. Journal of Comparative Physiology 149 (1):99-105. https://doi.org/10.1007/BF00735720

McVey, K. J., P. D. B. Skrade, and T. A. Sordahl. 2008. Use of a communal roost by turkey vultures in northeastern Iowa. Journal of Field Ornithology 79(2):170-175. https://doi.org/10.1111/ j.1557-9263.2008.00159.x

Meanly, B. 1965. The roosting behavior of the red-winged blackbird in the southern United States. Wilson Bulletin 77 (3):217-228. [online] URL: https://sora.unm.edu/sites/default/ files/journals/wilson/v077n03/p0217-p0228.pdf 
Mong, T. W., and B. K. Sandercock. 2007. Optimizing radio retention and minimizing radio impacts in a field study of upland sandpipers. Journal of Wildlife Management 71(3):971-980. https://doi.org/10.2193/2005-775

Morrell, L. J., and R. James. 2008. Mechanisms for aggregation in animals: rule success depends on ecological variables. Behavioral Ecology 19(1):193-201. https://doi.org/10.1093/ beheco/arm 122

Naef-Daenzer, B., F. Widmer, and M. Nuber. 2001. A test for effects of radio-tagging on survival and movements of small birds. Avian Science 1(1):15-23.

Nguyen, X. T., B. T. Nguyen, K. P. Do, Q. H. Bui, T. N. T. Nguyen, V. Q. Vuong, and T. H. Le. 2015. Spatial interpolation of meteorologic variables in Vietnam using the kriging method. Journal of Information Processing Systems 11(1):134-147. http:// dx.doi.org/10.3745/JIPS.02.0016

Obrecht, J. D., and S. J. Dinsmore. 2008. Weather factors influencing winter roosts of American crows in central Iowa. Journal of the Iowa Academy of Science 114(1-2):35-39. [online] URL: https://lib.dr.iastate.edu/nrem_pubs/90/

Petersen, A. J. 1955. The breeding cycle in the Bank Swallow. Wilson Bulletin 67:235-286. [online] URL: https://sora.unm.edu/ sites/default/files/journals/wilson/v067n04/p0235-p0286.pdf

Phillips, R. A., J. C. Xavier, and J. P. Croxall. 2003. Effects of satellite transmitters on albatrosses and petrels. The Auk 120 (4):1082-1090.

Plummer, M. V. 1977. Predation by black rat snakes in Bank Swallow colonies. Southwestern Naturalist 22(1):147-148. https:// doi.org/10.2307/3670484

Pyle, P. 1997. Identification guide to North American birds. Part I. Columbidae to Ploceidae. State Creek Press, Bolinas, California, USA.

Raim, A. 1978. A radio transmitter attachment for small passerine birds. Bird-Banding 49(4):326-332. https://doi.org/10.2307/4512391

Richner, H., and P. Heeb. 1996. Communal life: honest signaling and the recruitment center hypothesis. Behavioral Ecology 7 (1):115-118. https://doi.org/10.1093/beheco/7.1.115

Sauer, J. R., D. K. Niven, J. E. Hines, D. J. Ziolkowski Jr., K. L. Pardieck, J. E. Fallon, and W. A. Link. 2017. The North American breeding bird survey, results and analysis 1966-2015. Version 2.07.2017. U.S. Geological Survey Patuxent Wildlife Research Center, Laurel, Maryland, USA. [online] URL: https://www.mbrpwrc.usgs.gov/bbs/

Schulz, J. H., A. J. Bermudez, J. L. Tomlinson, J. D. Firman, and Z. He. 2001. Comparison of radiotransmitter attachment techniques using captive mourning doves. Wildlife Society Bulletin 29(3):771-782. [online] URL: https://www.jstor.org/ stable/3784401
Sirsat, S. K. G., T. S. Sirsat, A. Faber, A. Duquaine, S. Winnick, P. R. Sotherland, and E. M. Dzialowski. 2016. Development of endothermy and concomitant increases in cardiac and skeletal muscle mitochondrial respiration in the precocial Pekin duck (Anas platyrhynchos domestica). Journal of Experimental Biology 219:1214-1223. https://doi.org/10.1242/jeb.132282

Smiddy, P., C. Cullen, and J. O'Halloran. 2007. Time of roosting of barn swallows Hirundo rustica at an Irish reedbed during autumn migration. Ringing and Migration 23(4):228-230. https:// doi.org/10.1080/03078698.2007.9674369

Stolen, E. D., and W. K. Taylor. 2003. Movements of black vultures between communal roosts in Florida. Wilson Bulletin 115 (3):316-320. https://doi.org/10.1676/03-049

Stoner, D. 1936. Studies on the bank swallows, Riparia riparia riparia (Linnaeus) in the Oneida Lake region. Roosevelt Wild Life Bulletin 4:122-233.

Summers, R. W., G. E. Westlake, and C. J. Feare. 1987. Differences in the ages, sexes and physical condition of starlings Sturnus vulgaris at the centre and periphery of roosts. Ibis 129(1):96-102. https://doi.org/10.1111/j.1474-919X.1987.tb03164.X

Sykes, P. W. Jr., J. W. Carpenter, S. Holzman, and P. H. Geissler. 1990. Evaluation of three miniature radio transmitter attachment methods for small passerines. Wildlife Society Bulletin 18 (1):41-48. [online] URL: https://www.jstor.org/stable/3782307

Szép, T., and A. P. Møller. 2000. Exposure to ectoparasites increases within-brood variability in size and body mass in the sand martin. Oecologia 125:201-207. [online] URL: https://www. jstor.org/stable/4222764

Taylor, P. D., T. L. Crewe, S. A. Mackenzie, D. Lepage, Y. Aubry, Z. Crysler, G. Finney, C. M. Francis, C. G. Guglielmo, D. J. Hamilton, R. L. Holberton, P. H. Loring, G. W. Mitchell, D. Norris, J. Paquet, R. A. Ronconi, J. Smetzer, P. A. Smith, L. J. Welch, and B. K. Woodworth. 2017. The Motus Wildlife Tracking System: a collaborative research network to enhance the understanding of wildlife movement. Avian Conservation and Ecology 12(1):8. https://doi.org/10.5751/ACE-00953-120108

Walsberg, G. E., and J. R. King. 1980. The thermoregulatory significance of the winter roost-sites selected by robins in eastern Washington. Wilson Bulletin 92(1):33-39. [online] URL: https:// sora.unm.edu/sites/default/files/journals/wilson/v092n01/p0033-p0039. pdf

Ward, P., and A. Zahavi. 1973. The importance of certain assemblages of birds as "information-centres" for food-finding. Ibis 115(4):517-534. https://doi.org/10.1111/j.1474-919X.1973. tb01990.X

White, F. N., G. A. Bartholomew, and J. L. Kinney. 1978. Physiological and ecological correlates of tunnel nesting in the European Bee-eater, Merops apiaster. Physiological and Biochemical Zoology 51(2):140-154. https://doi.org/10.1086/ physzool.51.2.30157862 
Yom-Tov, Y. 1979. The disadvantage of low positions in colonial roosts: an experiment to test the effects of droppings on plumage quality. Ibis 121(3):331-333. https://doi.org/10.1111/j.1474-919X.1979. tb06852.x

Zuur, A. F., J. M. Hilbe, and E. N. Ieno. 2013. A beginner's guide to GLM and GLMM with R: a frequentist and Bayesian perspective for ecologists. Highland Statistics, Newburgh, UK.

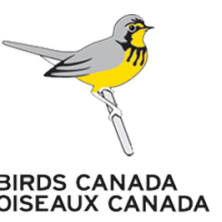

